\title{
Development of 3-D Hemispherical Biaxial Weft-Knitted Thermoset Composites
}

\author{
Özgür Demircan ${ }^{1}$, Tatsuya Kosui ${ }^{2}$, Shinsuke Ashibe² ${ }^{2}$ Asami Nakai ${ }^{3}$ \\ ${ }^{1}$ Metallurgical and Materials Engineering Department, Faculty of Engineering, Ondokuz Mayıs University, Samsun, Turkey \\ ${ }^{2}$ R\&D New Technology Applications, Shima Seiki Mfg. Ltd., Wakayama, Japan \\ ${ }^{3}$ Department of Mechanical and Systems Engineering, Faculty of Engineering, Gifu University, Gifu City, Japan
}

Corresponding Author: Özgür Demircan, ozgur.demircan@omu.edu.tr

\begin{abstract}
The present work concentrates on the development of 3-D hemispherical biaxial weft-knitted (BWK) thermoset composites. The objective is to improve the quality of the 3-D composites with BWK preform. Two kinds of the 3-D hemispherical BWK composites with the flat surfaced and 3-D dome shaped biaxial weft-knitted preforms were produced by hand lay-up method. The quantitative analysis of wrinkles was done by measuring the locking angles between the fiber bundles in the composites. Small numbers of wrinkle heights $(1$ height $/ 1 \mathrm{~cm})$ were observed on the flange surface of the 3-D hemispherical BWK composite with the dome shaped preform compared to the 3-D hemispherical BWK composite with the flat surfaced preform $(10$ heights $/ 1 \mathrm{~cm})$.
\end{abstract}

\author{
ARTICLE HISTORY \\ Received: 31.01.2019 \\ Accepted: 15.10.2019
}

\section{KEYWORDS}

biaxial weft-knitting, 3-D thermoset composites, locking angle, wrinkle of surface

\section{INTRODUCTION}

The architecture of the fiber reinforcement affects strongly the form ability of the composites. A material with good form ability will require low forming pressure and will demonstrates the lesser instability. Knitted fabrics have high drapeability and complex geometrical parts can be manufactured by knitting technology.

Until now a lot of researches were done on the development of hemispherical 3-D composites [1-6]. The drapeability of dry textile fabrics for stampable thermoplastic preforms was investigated by Rozant et al. [7]. They studied the mechanical behaviour and drapeability of some woven and knitted fabrics. The preliminary studies on single point incremental forming for composite materials were reported by Fiorotto et al. [8]. They formed aluminum and composite by single point incremental forming technique and conducted a compression test in order to compare the mechanical properties of materials. The experimental device for the preforming step of the RTM process was reported by Soulat et al. [9]. They developed tetrahedral and square punches and analyzed the evolution of preform of woven process, such as wrinkles and bucklings. They showed that preforming quality can be affected from the punch geometry, the number and the position of blank holders and values of pressure punch strokes and speeds. Vanclooester et al. [10] optimized deep drawing of multilayered fabric composites and found out thicker preforms reduce the wrinkles of composites.

Because, the fabrication method of the biaxial weft-knitted fabrics was comparatively very new compare to the traditional knitting fabrics, it was very necessary to fabricate the 3-D composites with the BWK fabric. Additionally, there was found no research about the 3-D hemispherical BWK thermoset composites, which was produced with the dome shaped BWK preform. Also, we found no study about the 3-D dome shaped BWK preform, which was produced by the knitting machine. In this study, we would like to show the shapeability of the biaxial weftknitted composites. The present work concentrates on the

To cite this article: Demircan Ö, Kosui T, Ashibe S, Nakai A. 2019. Development of 3-D Hemispherical Biaxial Weft-Knitted Thermoset Composites. Tekstil ve Konfeksiyon 29(4), 305-310. 
development of the 3-D hemispherical biaxial weft-knitted thermoset composites.

\section{MATERIAL AND METHOD}

\subsection{Material}

330 tex and 44 tex aramid yarns (Kevlar 29, Toray Dupon Co. Ltd., Japan) were used as reinforcement and stitch yarns (Table 1). The wale density (wale/cm) was 2 end/cm, course density (course/cm) was $10 \mathrm{end} / \mathrm{cm}$ and machine gauge (needles/inch) was 18 needles/inch. Vinyl ester resin (Ripoxy R-806, Showa High Polymer Co. Ltd., Japan) was used as matrix. The curing agent (methyl ethyl ketone peroxide (PERMEK® N)) was obtained from NOF Corporation, Japan. Thin and flexible polypropylene (PP) film (Futamura Kogac Ltd., Japan) was used during fabrication of the composite panels. The biaxial plain weft- knitted fabrics were produced on a flat bed knitting machine (Shima Seiki Mfg., Ltd., Japan). The schematic drawing of the BWK fabric is shown in Figure 1. The biaxial weft-knitted fabric structures had same plain knitted loop architecture. The flat surfaced and dome shaped BWK structures are shown in Figure 2a, b. There was ellipse shapes on the surface of the dome shaped biaxial weftknitted fabric. The ellipse shapes were given by a special knitting technique (short row knitting) during fabrication of the BWK fabric (Figure 2c, d). In knitting, a short row is a row that is not fully knitted; the work is turned before reaching the end of the row. Just before the work is turned, the yarn is generally passed around the next unknitted stitch. When dome shaped biaxial weft-knitted specimen was produced on the machine, it had a flat surface. The dome shape was given by hand in a second process (Figure 3). The flat surfaced and dome shaped BWK materials were prepared by Shima Seiki Mfg. Ltd., Japan.

Table 1. Parameters of the BWK fabric

\begin{tabular}{ccccc}
\hline Sample name & $\begin{array}{c}\text { Biaxial } \\
\text { (warp and } \\
\text { weft) yarns }\end{array}$ & Stitch yarn & $\begin{array}{c}\text { Density of warp } \\
\text { yarn in fabric } \\
\text { (end/cm) }\end{array}$ & $\begin{array}{c}\text { Density of weft yarn } \\
\text { in fabric } \\
\text { (end/cm) }\end{array}$ \\
\hline $\begin{array}{c}\text { Biaxial weft- } \\
\text { knitted, aramid }\end{array}$ & $\begin{array}{c}\text { AR } \\
330 \text { Tex }\end{array}$ & $\begin{array}{c}\text { AR } \\
\text { 4Tex }\end{array}$ & 2 & 10 \\
\hline
\end{tabular}

AR: Aramid

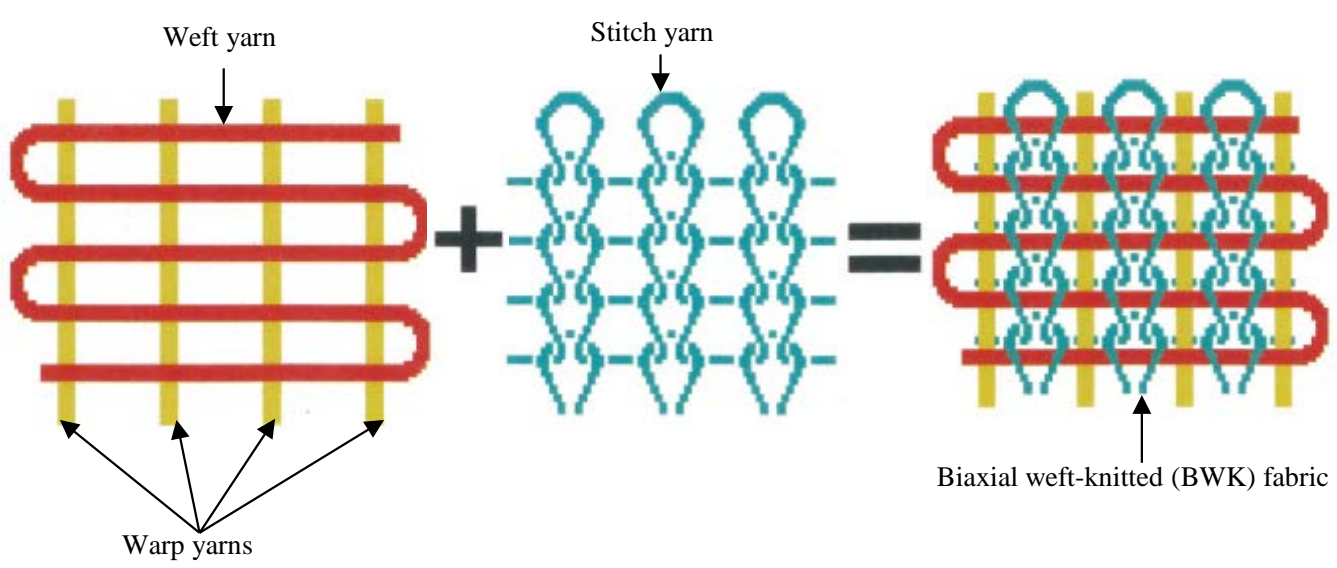

Figure 1. Schematic drawing of biaxial weft-knitted (BWK) preform

\subsection{Method}

In order to fabricate the 3-D composites, at first, the one layer BWK fabrics were impregnated with resin on a flat space of a table; the bottom and top surfaces of the resin impregnated BWK fabrics were covered with a film. After a few seconds, they were put into the PU molds. Polyurethane (PU) foam was used for the lower and upper molds. A special (thin and flexible) polypropylene (PP) film, Futamura Kogac Ltd., Japan, with 0.03 mm thickness was used during impregnation of the resin into the BWK fabric. Two kinds of the one ply composite panels were fabricated by hand lay-up lamination method: (i) 3-D hemispherical BWK composite with flat surfaced fabric, (ii) 3-D hemispherical BWK composite with dome shaped fabric. The average thickness and the fiber volume fraction of the 3-D composite panels were about $2.0 \mathrm{~mm}$ and $35 \%$ respectively. 
a)

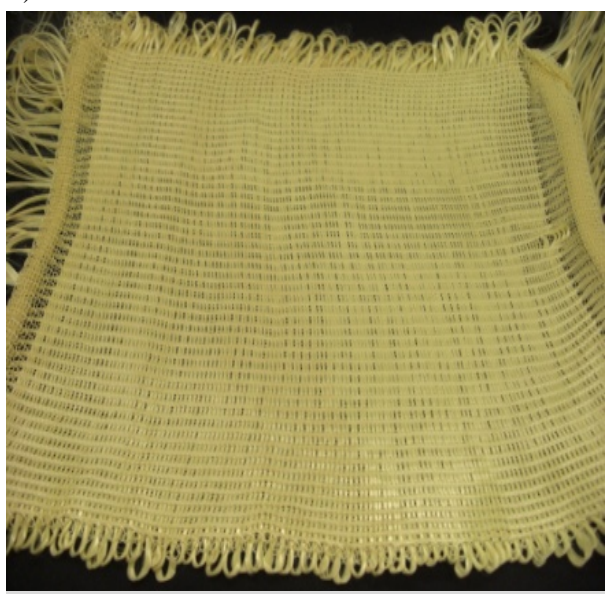

Flat surfaced BWK fabric

c)

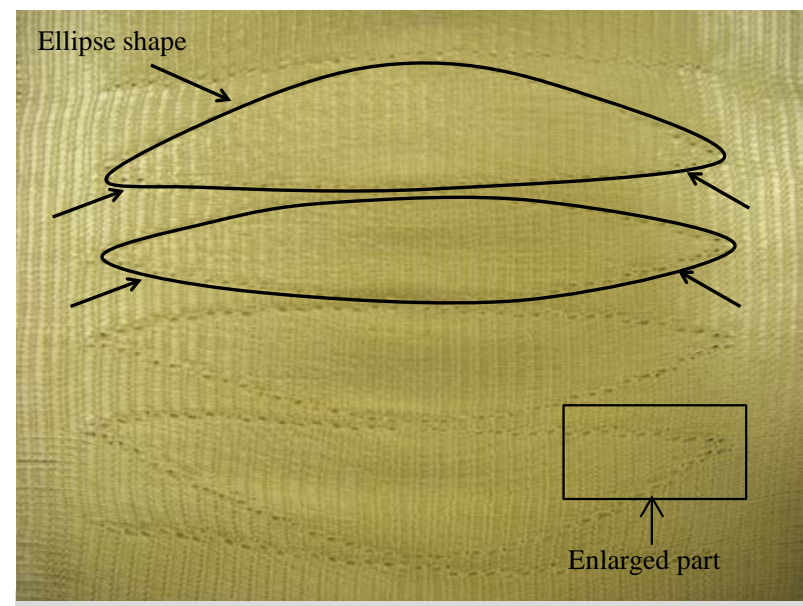

Surface of dome shaped BWK fabric b)

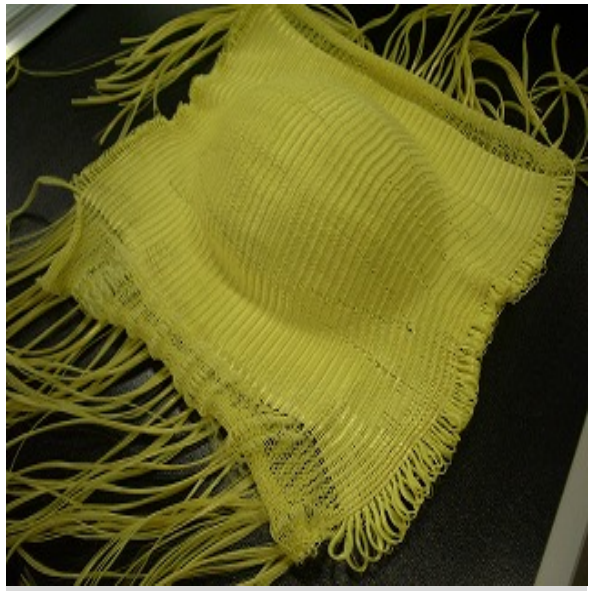

Dome shaped BWK fabric

d)

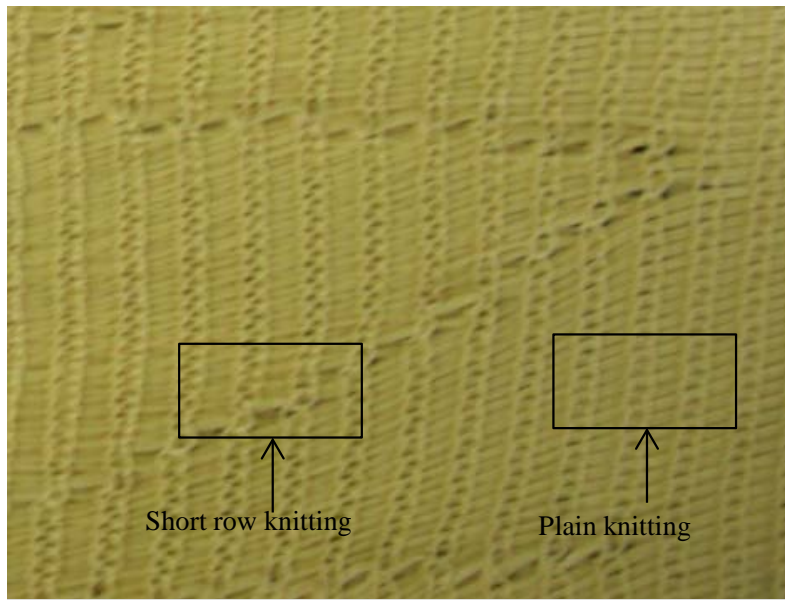

Enlarged part of surface of dome shaped BWK fabric

Figure 2. Biaxial weft-knitted (BWK) preforms a) flat surfaced, b) dome shaped, c) ellipse shapes on the surface of dome shaped BWK, d) enlarged part of the ellipse shape (short row knitting and plain knitting)

a)

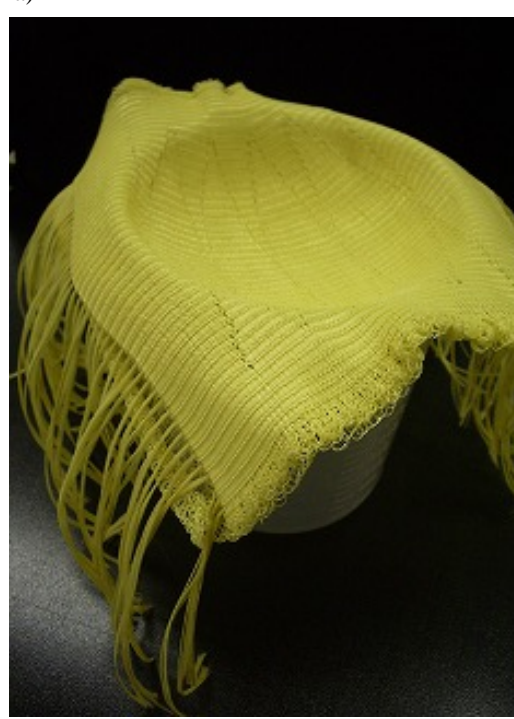

b)

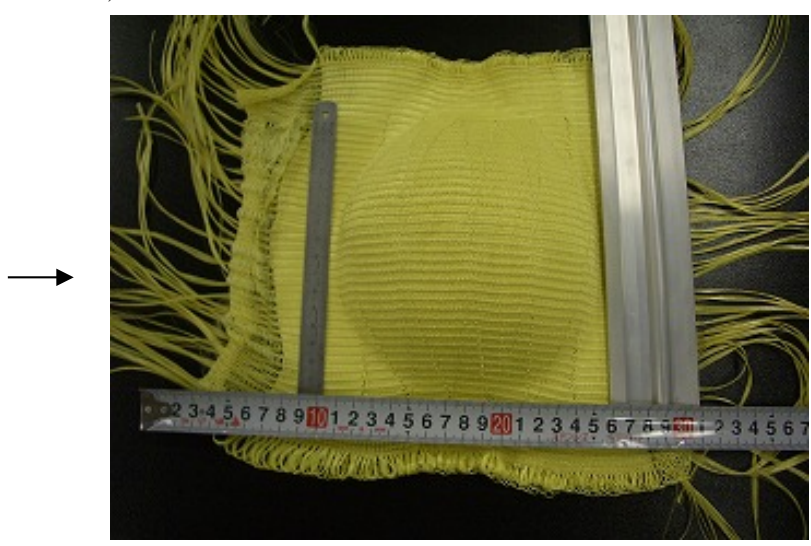

Figure 3. Photographs of preparation of 3-D dome shaped preforms 


\subsection{Locking Angle}

The states of the fibres before and after deformation can be seen in Figure 4a, b. Before starting deformation of the fabric, the initial angle between the warp and weft biaxial fiber bundles was $90^{\circ}$. As the fabric deformed, the density of the warp and weft biaxial fiber bundles per unit area increased. After the first deformation, when we continued to further deformation, the critical shearing angle (locking angle) was reached. Thus, this angle can be used as a characteristic value for describing of the initial point of the wrinkles on the fabric surface.

\section{RESULTS AND DISCUSSION}

\subsection{Effect of Locking Angle}

In this part, the wrinkles on the surfaces of the composites were analyzed by quantitatively. Figure 5a, b demonstrates positions of the locking angles between the fiber bundles in the 3-D hemispherical BWK composite with dome shaped preform. Due to the wrinkles occurred on the surface of the 3-D composites with the BWK preforms, we understood that the locking angles were reached for all the measurements. In Figure 5a, b, the locking angles were measured in 12 different positions from $0^{\circ}$ to $45.1^{\circ}$ in the $3-$ D hemispherical BWK composites.

A comparison of the locking angle versus is shown in Figure 6. During deformation without wrinkling is required for the forming into the complex shapes of the BWK composites, low locking angles are desired. The measured locking angles were agreed with amount of the wrinkle heights. The locking angles were reduced in both composites in positions from $0^{\circ}$ to $45.1^{\circ}$.

At the same measured points, the composites with the dome shaped BWK preforms had lower locking angles, than the composites with the flat shaped BWK preforms. For example, the locking angles were $45^{\circ}$ (flat shaped) and $20^{\circ}$ (dome shaped) in positions at $33^{\circ}$. The ellipse shapes on the surface of the dome shaped BWK preforms in the dome shaped BWK composites would be reason of the lower locking angle compared to that was with the flat surfaced BWK preforms.

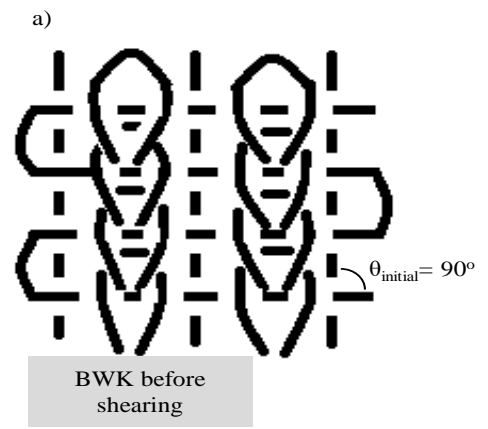

b)

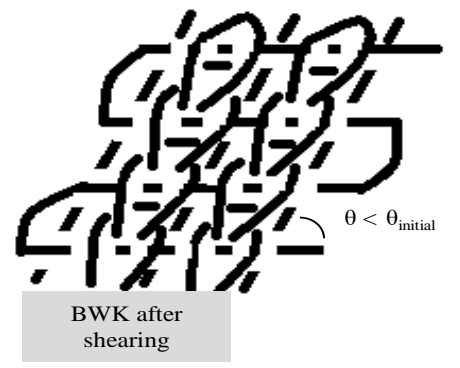

Figure 4. $a$ and $b$ states of the fibres before and after deformation

a)

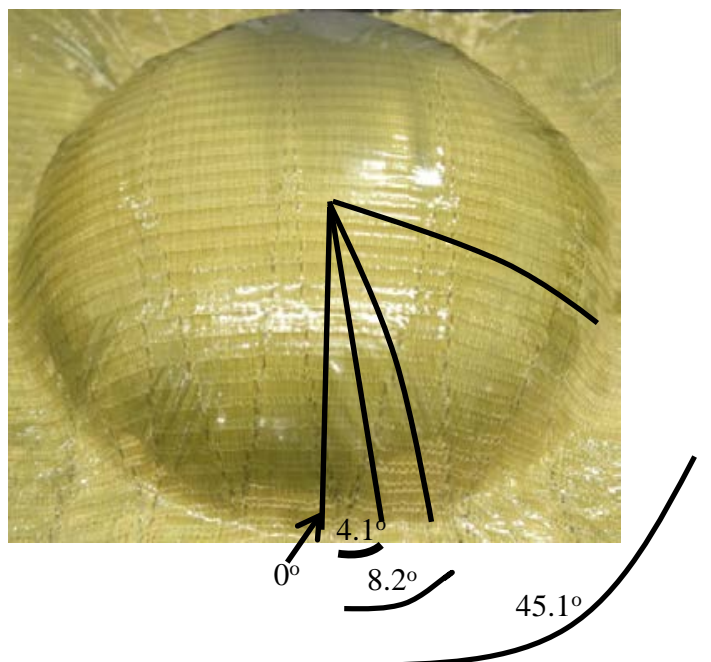

b)

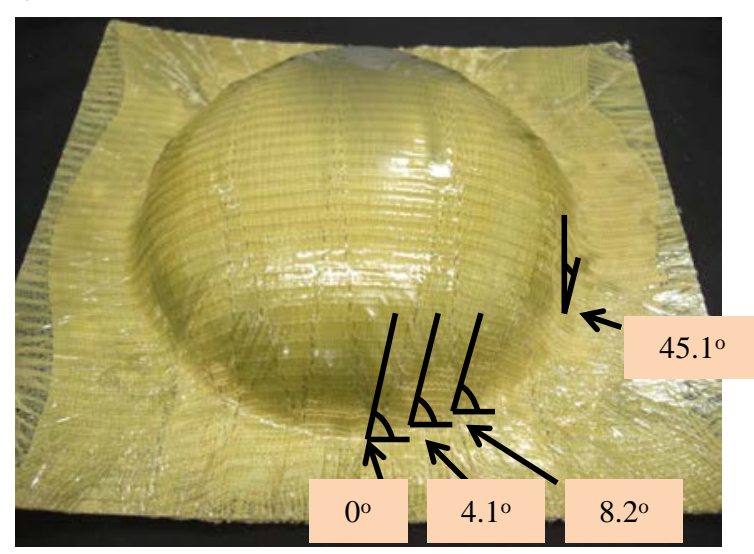

Figure 5. a and b positions of the locking angles between the fiber bundles in the 3-D hemispherical BWK composite 


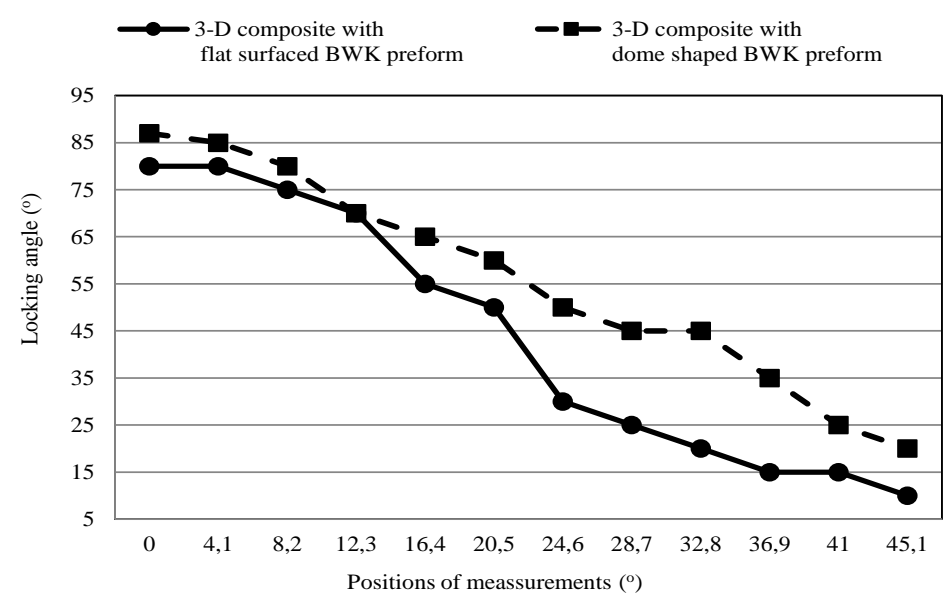

Figure 6. Comparison of locking angles of specimens

\subsection{Surface Characteristics of the 3-D Composites}

Two kinds of the composites, (i) 3-D hemispherical BWK composite with flat surfaced fabric (Figure 7a, b), (ii) 3-D hemispherical BWK composite with dome shaped fabric (Figure $7 \mathrm{c}, \mathrm{d}$ ), were produced with the same processing conditions, such as same weight pressure, PP film, curing conditions and etc. After fabricating of two kinds of the composite panels, amount of the wrinkles were analyzed by taking the digital photographs. The enlarged parts of the composites are shown in Figure $7 \mathrm{~b}$ and $7 \mathrm{~d}$. Large numbers of wrinkle heights (10 heights $1 \mathrm{~cm})$ were observed on the flange of the 3-D hemispherical BWK composites with the flat surfaced preform (Figure 7b). However, small numbers of wrinkle heights $(1$ height $/ 1 \mathrm{~cm})$ were observed on the flange surface of the 3-D hemispherical BWK composites with the dome shaped preform, which is shown in Figure $7 \mathrm{~d}$. The preshaped BWK fabric can easier takes the hemispherical dome shape than the initially flat fabric which was stabilized by the knitted yarns. Therefore, pre-shaped BWK fabrics could be used to fabricate complex 3-D composite materials with a high quality.
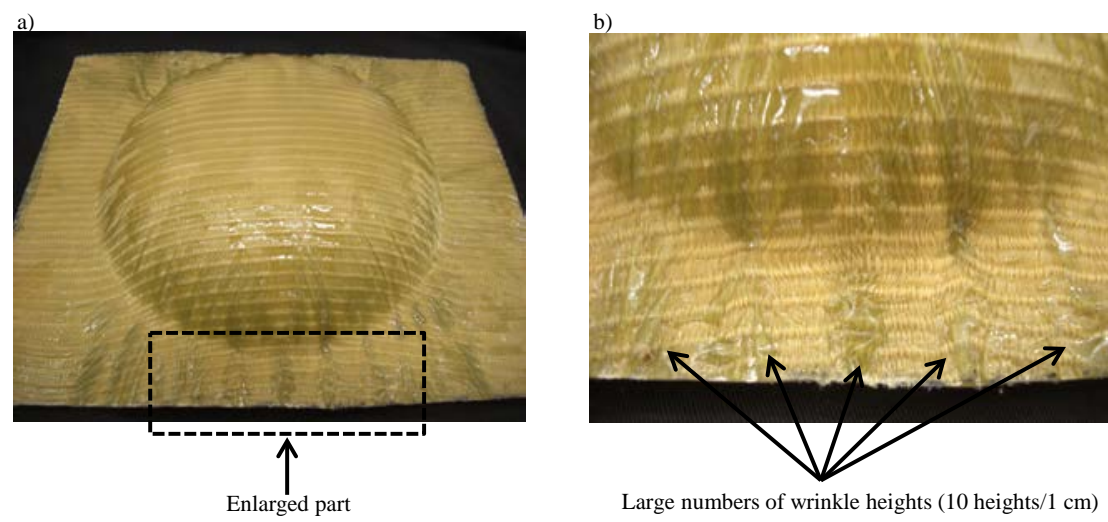

3-D BWK composite with flat surfaced BWK fabric
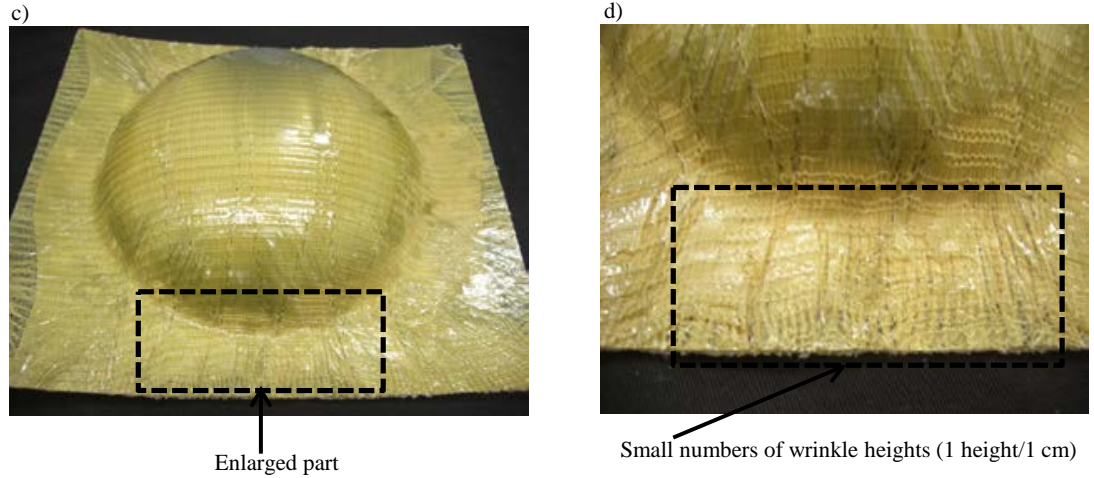

3-D BWK composite with dome shaped BWK fabric

Figure 7. a) 3-D hemispherical BWK composite with flat surfaced preform, b) enlarged part of 3-D hemispherical BWK composite with flat surfaced preform, c) 3-D hemispherical BWK composite with dome shaped preform, d) enlarged part of 3-D hemispherical BWK composite with dome shaped preform 


\section{CONCLUSION}

The hand lay-up technique was applied to fabricate the 3-D hemispherical composites. Two kinds of the 3-D composites were produced with same processing conditions. The wrinkles characteristics of the composites were analyzed and found out the 3-D hemispherical BWK composites with the dome shaped preform had small numbers of wrinkle heights compared to the 3-D hemispherical BWK composites with the flat surfaced preform. This study showed that the complex 3-D structures can be produced by the biaxial weft-knitting technique and the quality of the composite materials, such as small numbers of wrinkle heights on the surface of the composites, could be improved using 3-D preforms. In future study, thermoplastic biaxial weft-knitted hemispherical composites will be produced by hot compressing method and the influence of the different preform styles on the mechanical properties of the composites will be to investigated.

\section{ACKNOWLEDGEMENT}

The authors thank to Prof. Hiroyuki Hamada and Dr. Eng. Mohamed S. Aly-Hassan, Kyoto Institute of Technology for their help and support.

\section{REFERENCES}

1. Fangueiro R, Nunes P, Soutinho F, Araujo MD. 2009. Development of fibrous preforms for FRP pipe connections. Composites Science and Technology 69, 1412-1416.

2. Dufour C, Wang P, Boussu F, Soulat D. 2014. Experimental investigation about stamping behaviour of 3D warp interlock composite preforms. Applied Composite Materials 21, 725-738.

3. Wang P, Legrand X, Boisse P, Hamila N, Soulat D. 2015. Experimental and numerical analyses of manufacturing process of a composite square box part: Comparison between textile reinforcement forming and surface 3D weaving. Composites Part B: Engineering 78, 26-34.

4. Liu LS, Zhang T, Wang P, Legrand X, Soulat D. 2015. Influence of the tufting yarns on formability of tufted 3-Dimensional, composite reinforcement. Composites Part A: Applied Science and Manufacturing 78, 403-411.

5. Cherouat A, Borouchaki H, Laurence GM, 2010. Mechanical and geometrical approaches applied to composite fabric forming. International Journal of Material Forming. 3, 1189-1204.
6. Mossea L, Compstona P, Cantwell WJ, Cardew-Hall M. Kalyanasundaram S. 2006. Stamp forming of polypropylene based fibre-metal laminates: The effect of process variables on formability. Journal of Materials Processing Technology 172, 163-168.

7. Rozant O, Bourban PE, Manson JAE. 2000. Drapeability of dry textile fabrics for stampable thermoplastic preforms. Composites Part A Applied Science and Manufacturing 31, 1167-1177.

8. Fiorotto M, Sorgente M, Lucchetta G. 2010. Preliminary studies on single point incremental forming for composite materials. Journal of Materials Science 3, 951-954.

9. Soulat D, Allaoui S., Chatel S. 2009. Experimental device for the preforming step of the RTM process. Journal of Materials Science 2, 181-184.

10. Vanclooester K, Goidsenhoven GV, Lomov SV, Verpoest I. 2009. Optimizing the deepdrawing of multilayered woven fabric composites. 12th ESAFORM Conference on Material Forming, Twente, the Netherlands. 